\title{
Corrigendum to "Predictive Value of Plasma MicroRNA-216a/b in the Diagnosis of Esophageal Squamous Cell Carcinoma"
}

\author{
Shuling Dong, ${ }^{1,2}$ Huiqing Yin, ${ }^{1,2}$ Cuicui Dong, ${ }^{1,2}$ Kaiyan Sun, ${ }^{1,2}$ Pin Lv, ${ }^{1,2}$ Weiwei Meng, ${ }^{3}$ \\ Liang Ming, ${ }^{1,2}$ and Fucheng $\mathrm{He}^{1,2}$ \\ ${ }^{1}$ Department of Medical Laboratory, The First Affiliated Hospital of Zhengzhou University, Zhengzhou, Henan 450052, China \\ ${ }^{2}$ Key Medical Laboratory of Henan Province, Zhengzhou, Henan 450052, China \\ ${ }^{3}$ Department of Medical Laboratory, The Second Affiliated Hospital of Zhengzhou University, Zhengzhou, Henan 450052, China
}

Correspondence should be addressed to Liang Ming; mingliang3072@163.com and Fucheng He; hefucheng@126.com

Received 29 June 2016; Accepted 12 October 2016; Published 12 March 2017

Copyright (c) 2017 Shuling Dong et al. This is an open access article distributed under the Creative Commons Attribution License, which permits unrestricted use, distribution, and reproduction in any medium, provided the original work is properly cited.

In the article titled "Predictive Value of Plasma MicroRNA$216 \mathrm{a} / \mathrm{b}$ in the Diagnosis of Esophageal Squamous Cell Carcinoma" [1], there was an error in Table 1 . The heading incorrectly referred to miRNA-718 expression instead of miRNA-216a/b. miRNA-718 expression is the subject of a related article, Sun L, Dong S, Dong C, Sun K, Meng W, Lv P, Yin H, Ming L, He F: "Predictive value of plasma miRNA718 for esophageal squamous cell carcinoma". Cancer Biomark. 2016;16(2):265-73. doi: 10.3233/CBM-150564. The table should be corrected as follows.

TABLE 1: Clinicopathological characteristics of patients with ESCC.

\begin{tabular}{|c|c|c|c|c|c|}
\hline \multirow{2}{*}{ Characteristics } & \multirow{2}{*}{$n(\%)$} & \multicolumn{4}{|c|}{ Plasma miRNA relative expression level $($ mean \pm SD) } \\
\hline & & miR-216a & $P$ value & miR-216b & $P$ value \\
\hline Age (year) & & & 0.1082 & & 0.2125 \\
\hline$\leq 63$ & $46(38.3)$ & $0.058 \pm 0.048$ & & $0.079 \pm 0.086$ & \\
\hline$>63$ & $74(61.7)$ & $0.074 \pm 0.054$ & & $0.099 \pm 0.087$ & \\
\hline Gender & & & 0.5388 & & 0.5912 \\
\hline Male & $79(65.8)$ & $0.070 \pm 0.055$ & & $0.094 \pm 0.087$ & \\
\hline Female & $41(34.2)$ & $0.064 \pm 0.048$ & & $0.085 \pm 0.089$ & \\
\hline Smoking & & & 0.1342 & & 0.6168 \\
\hline Never & $52(43.3)$ & $0.060 \pm 0.047$ & & $0.087 \pm 0.079$ & \\
\hline Ever & $68(56.7)$ & $0.074 \pm 0.056$ & & $0.095 \pm 0.093$ & \\
\hline Alcohol use & & & 0.2378 & & 0.5386 \\
\hline Never & $40(33.3)$ & $0.060 \pm 0.054$ & & $0.098 \pm 0.087$ & \\
\hline Ever & $80(66.7)$ & $0.072 \pm 0.051$ & & $0.088 \pm 0.087$ & \\
\hline
\end{tabular}


TABle 1: Continued.

\begin{tabular}{|c|c|c|c|c|c|}
\hline \multirow{2}{*}{ Characteristics } & \multirow{2}{*}{$n(\%)$} & \multicolumn{4}{|c|}{ Plasma miRNA relative expression level $($ mean \pm SD) } \\
\hline & & miR-216a & $P$ value & miR-216b & $P$ value \\
\hline Tumor location & & & 0.3136 & & 0.1810 \\
\hline Upper esophagus & $11(9.2)$ & $0.065 \pm 0.061$ & & $0.106 \pm 0.092$ & \\
\hline Middle esophagus & $70(58.3)$ & $0.074 \pm 0.056$ & & $0.100 \pm 0.096$ & \\
\hline Low esophagus & $39(32.5)$ & $0.058 \pm 0.041$ & & $0.072 \pm 0.066$ & \\
\hline Histologic grade & & & 0.8959 & & 0.8308 \\
\hline Well differentiated & $33(27.5)$ & $0.070 \pm 0.059$ & & $0.109 \pm 0.112$ & \\
\hline Moderate differentiated & $70(58.3)$ & $0.068 \pm 0.052$ & & $0.089 \pm 0.082$ & \\
\hline Poor differentiated & $17(14.2)$ & $0.063 \pm 0.040$ & & $0.068 \pm 0.030$ & \\
\hline T stage & & & 0.3206 & & 0.6600 \\
\hline Tis-T1 & $36(30.0)$ & $0.075 \pm 0.061$ & & $0.115 \pm 0.114$ & \\
\hline $\mathrm{T} 2$ & $28(23.3)$ & $0.086 \pm 0.065$ & & $0.100 \pm 0.090$ & \\
\hline $\mathrm{T} 3$ & $41(34.2)$ & $0.056 \pm 0.037$ & & $0.074 \pm 0.065$ & \\
\hline $\mathrm{T} 4$ & $15(12.5)$ & $0.050 \pm 0.019$ & & $0.067 \pm 0.031$ & \\
\hline Lymph node metastasis & & & 0.0845 & & 0.0168 \\
\hline Negative & $42(35.0)$ & $0.088 \pm 0.068$ & & $0.134 \pm 0.117$ & \\
\hline Positive & $78(65.0)$ & $0.057 \pm 0.038$ & & $0.068 \pm 0.054$ & \\
\hline TNM stage & & & 0.0054 & & 0.0359 \\
\hline $0-\mathrm{I}$ & $29(24.2)$ & $0.088 \pm 0.062$ & & $0.134 \pm 0.119$ & \\
\hline II & $28(23.3)$ & $0.086 \pm 0.065$ & & $0.101 \pm 0.090$ & \\
\hline III & $40(33.3)$ & $0.058 \pm 0.035$ & & $0.072 \pm 0.067$ & \\
\hline IV & $23(19.2)$ & $0.039 \pm 0.022$ & & $0.060 \pm 0.029$ & \\
\hline
\end{tabular}

\section{References}

[1] S. Dong, H. Yin, C. Dong et al., "Predictive value of plasma MicroRNA-216a/b in the diagnosis of esophageal squamous cell carcinoma," Disease Markers, vol. 2016, Article ID 1857067, 8 pages, 2016. 


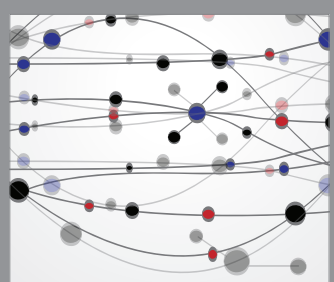

The Scientific World Journal
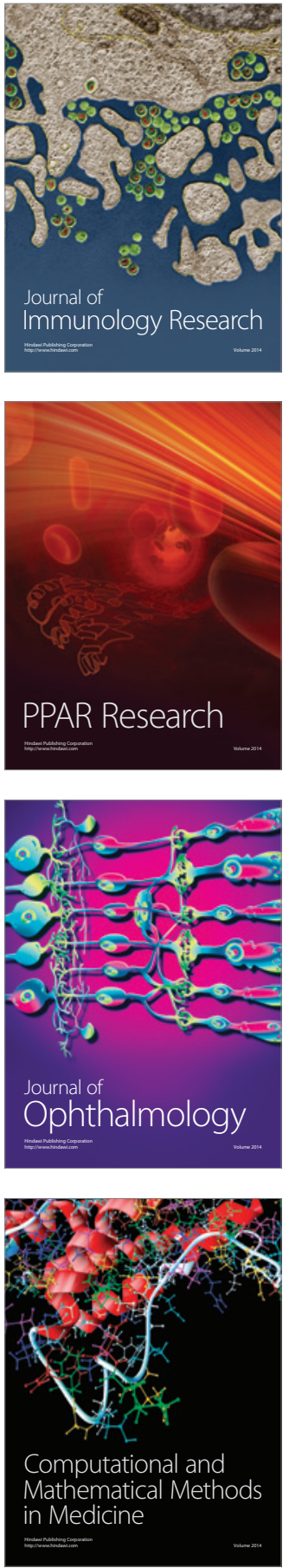

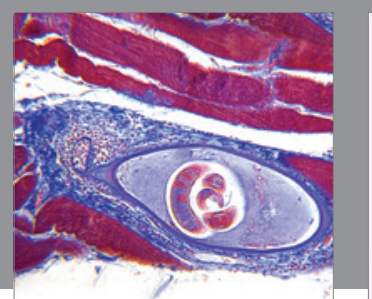

Gastroenterology Research and Practice
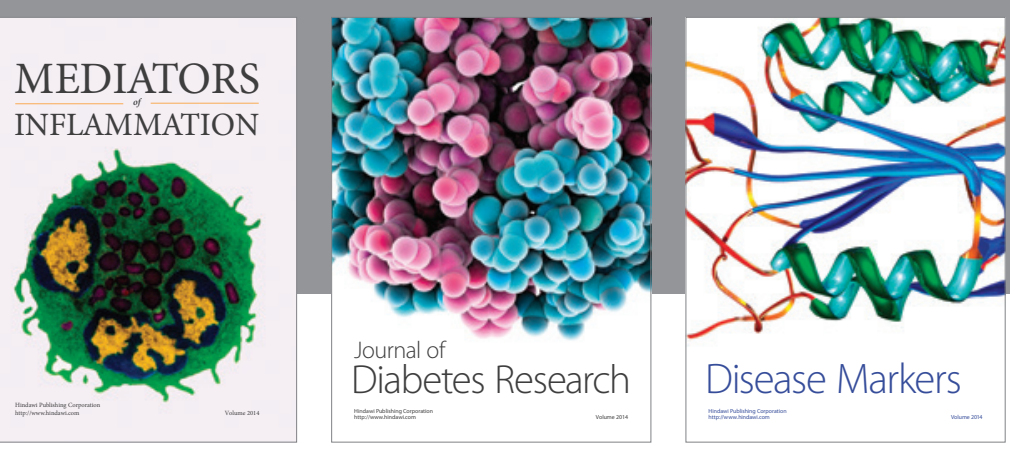

Disease Markers

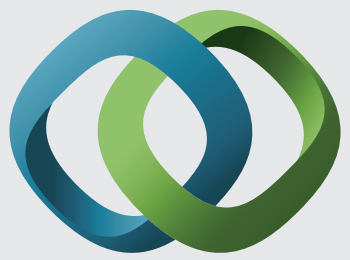

\section{Hindawi}

Submit your manuscripts at

https://www.hindawi.com
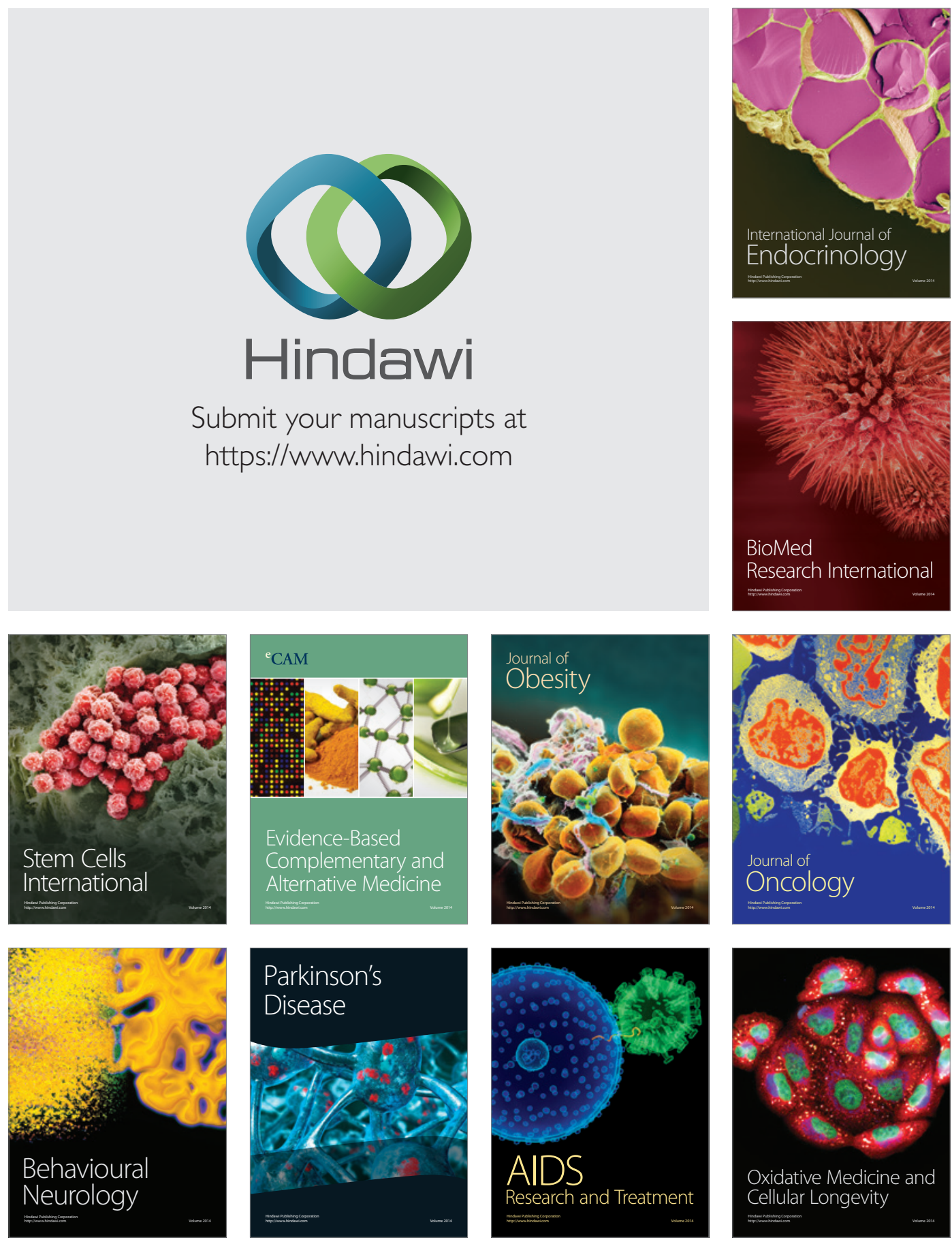